\begin{tabular}{lccr} 
A R C H I E & O F & M E C H A N I C A L & E N G I N E E R I N G \\
\hline VOL. LXIII & 2016 & Number 1
\end{tabular}

10.1515/meceng-2016-0009

Key words: steam turbine, structural and creep analysis, modal analysis, FEM

PAWEŁ BORKOWSKI *, DOMINIK GŁOWACKI *, AGNIESZKA NOWAKOWSKA *, JAKUB PAWLICKI* JANISEAW ZWOLIŃSKI*

\title{
FE ANALYSIS OF A STEAM TURBINE HP ROTOR BLADE STAGE CONCERNING MATERIAL EFFORT, DYNAMIC PROPERTIES AND CREEP DAMAGE ASSESSMENT
}

\begin{abstract}
This paper is concerned with the $1^{\text {st }}$ stage of HP rotor blade assembly steam turbine TK 120. The methodology was focused on the selection of mechanical properties and the way of the rotor disc modeling and estimating the degree of damage caused by creep. Then the dynamic interference between the frequencies of excitation and the natural frequencies was assessed. Static calculations were performed for the cyclic sectors consisting of the disc, disc blades, spacers and shrouding, including loads as temperature, mass forces from the angular velocity and the pressure on the blades. Then, the creep analysis using a Norton's model and the modal analysis were performed. Static analysis gave information concerning the distributions of displacements, stress and strain components. In the creep analysis, the creep displacements and stress relaxation versus time were determined and the estimated degree of damage caused by creep was evaluated at each part of the rotor disc. In the modal analysis, the natural frequencies and modes of vibrations corresponding to the nodal diameters were found. The results of modal analysis were shown in the SAFE graph. Numerical calculations have shown that the rotor disc was a well-designed structure and did not reveal any dynamic interference.
\end{abstract}

\section{Introduction}

The issue presented in this paper have been already undertaken by many researchers. Hormozi et al. [9] conducted the analysis of the creep damage assessment by application of the material tests to validate the finite element model. The specimens were loaded cyclically. A linear damage summation method was used to include the damage caused both by the creep and the

* Warsaw University of Technology, Institute of Aeronautics and Applied Mechanics, Nowowiejska 24, 00-665 Warszawa, Poland; E-mails: pbork@meil.pw.edu.pl; dglowacki@meil.pw.edu.pl; kubap@meil.pw.edu.pl; jzwolin@meil.pw.edu.pl 
fatigue. The creep constants were evaluated on the basis of testing and then implemented to the finite element model, and a good agreement was achieved. An example of the material degradation in the turbine rotor disc after 40 years of the exploitation period was described in [10]. The location of cracks in the disc grove was presented and the procedure of reparation was described. The authors stated that the degradation was caused by the stress corrosion cracking, but it probably was influenced by the creep. In the paper [11], the finite element model of the turbine blade with a simplified geometry was presented and the accumulated summary damage criterion including the creep, corrosion and fatigue was assessed. The accumulated criterion was based on the Neu-Sehitoglu thermo mechanical fatigue formula. This approach resulted in about two times shorter life time in comparison to the case where the damage components were considered separately. The disadvantage of this criterion was the requirement for the nineteen material data. Reyhani et al. [12] conducted the 3-D finite element analysis of the turbine blade including the creep and fatigue. Although they used LarssonMiler parameter to the creep damage assessment, this part of damage was evaluated on the basis of the initial stress state, which was a significant simplification because the stress relaxation was not taken into account. In the work [13], the creep damage parameter was included in the creep law formula given by Leckie-Hayhurst. The model was artificially divided into two parts represented by tension members. The damage in the creep-elastic part was developing with time and the stress redistribution was resulting in the load transfer to the strictly elastic part. Thus the damage was not related to the whole structure and finally the elastic part of structure kept the entire load. The example of the failure assessment was the creep analysis of the valve shown in [14]. The secondary and tertiary creep was analyzed. The authors defined the creep rate as the sum of the linear and the powerlaw stress functions and considered the ductile and brittle types of failure according, respectively, to the Hoff's and Rabotnov's criteria. This approach was related to the third creep period characterized by the increasing creep rate. Consequently, the appropriate material data for this period were required which are often not available.

This article presents the practical application of the creep damage theory described in [6], which was based on the available material data including the creep tests results obtained from the literature [3,5] and the results of the structural FE creep analysis by using the commercial software. The numerical structural analysis of the rotor disc of an impulse steam turbine was a part of a wider research aimed at determining the criteria for acceptance of the existing turbine for further exploitation and at establishing the guidelines for 
FE ANALYSIS OF A STEAM TURBINE HP ROTOR BLADE STAGE CONCERNING MATERIAL EFFORT,.. 165

renovation work. The scope and purpose of the simulation was consulted in cooperation with the ZRE "Katowice" company.

The stress state of the rotor disc and its dynamic characteristic may vary in time and change due to the repair operations. Rheological phenomena in turbines caused by the long-term steady loads result in a change of dimensions of the parts as a result of creep. Significant changes in the material at the micro-scale level in a form of phase transitions from bainite to perlite, separations on grain boundaries and finally creep voids can be followed by micro-cracks initiation and their subsequent joining. These changes at the macro scale lead to creep failure or excessive reduction of the blade clearances, which in extreme cases may lead to the damage of the turbine. In addition, the stress relaxation also occurs in time, which is especially important in the regions of connections between the rotor disc and the turbine shaft. Loosening of the interference between the parts may have a significant effect on the dynamic characteristics of the shaft, including the natural frequencies and the shape of vibrations.

Long-lasting load combined with the high temperature produces a gradual degradation of the material in the micro scale $[6,10]$, which may lead to cracking. Evaluation of the life time and the level of material damage can prevent the degradation and may be helpful to decide on further exploitation.

The materials which are used in Poland to make turbine components do not always have their replacements in other countries [3, 5]. This is the reason for the lack of availability of the data concerning the thermo-mechanical material properties and, particularly, the rheological parameters. It affects the quality of the results of the numerical analysis, used here as a tool for the stress state analysis, dynamic properties and the damage assessment [7, 8].

\section{Material and methods}

The analyses were performed on the discrete structural models using the finite element method. The $1^{\text {st }}$ stage of HP rotor blade assembly (A1) of the turbine TK120 model consists of a disc connected integrally with the turbine shaft and containing a total of 156 blades subdivided into 8 packages of 13 blades and 4 packages of 12 blades coupled by shroud segments. Turbine casing and the stator were not included in the model.

The cyclic model of a single sector before modification was based on the real geometry and contained a part of the disc, the blade, the shroud and the spacer which was artificially divided into two parts (Fig. 1). In this model, the shroud was modeled as a continuous ring. Both parts of the spacer were linked together by the cyclic symmetry conditions in order to ensure 

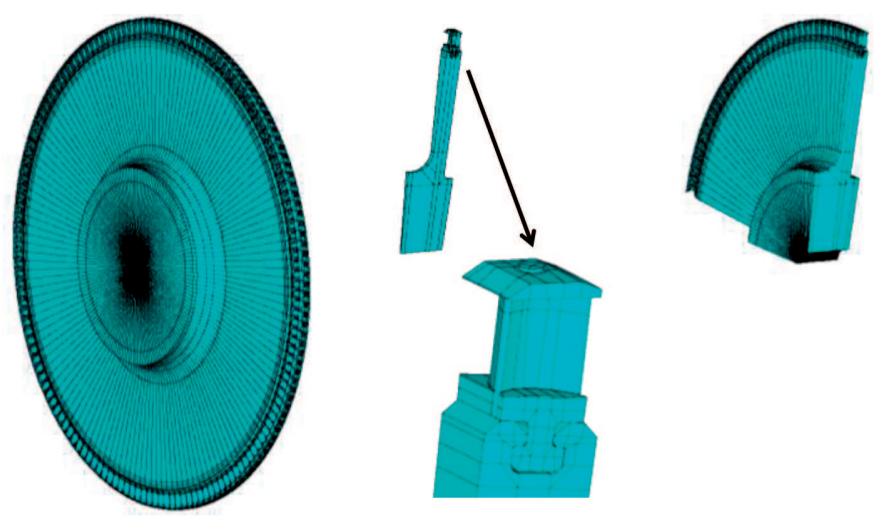

Fig. 1. Model of A1 rotor disc: a single cyclic sector and the one quadrant of the disc

the continuity. The angle of the sector was $2.3682^{\circ}$ ( $360^{\circ} / 152$ blades). The modified cyclic sector model was used to study the effect of the division of the shroud, and had 39 blades $(13+13+13)$ in a quadrant of the rotor, thus the total number of blades on the circumference was $156(39 \cdot 4)$. The cyclic model of the sector after modification was similar to the real geometry and contained a larger part of the disc, 13 blades connected with one shroud (sector angle was $360^{\circ} / 12=30^{\circ}$ ) and 13 spacers. In this model, the shroud was modeled as the continuous or discontinuous ring (partially continuous). The considered cases were described in the Tab. 1. The calculations were performed using the ANSYS system [2]. The thermal analysis of the A1 stage was performed in order to adjust the nodal temperatures to the results of the thermal transient analysis including the whole turbine shaft, which was not presented in this paper. The time period of the turbine start-up was neglected and the structural analyses were performed for the constant thermal conditions, thus the analyses were uncoupled. The eight-node finite elements SOLID185 with the option of integrating Enhanced Strain were used in the structural analysis, and their equivalents SOLID70 were applied in the thermal analysis. The standard contact with a friction coefficient of 0.1 was assumed between separate parts of the rotor disc, and the surface elements CONTA174 and TARGE170 were applied on the contact surfaces. The mechanical contact was solved using the penalty-based contact method and the Augmented Lagrange formulation. The thermal contact was also based on default options, but because of the fact that the temperature in the outer part of the rotor disc was nearly constant (Fig. 4), the influence of the misfit between the contacting surfaces on the heat transfer between adjacent parts was rather not significant. The cyclic model of a single sector contained about 46,000 finite elements and 53,000 nodes. The sparse solver was used to find the solutions of the structural and modal problems. 
FE ANALYSIS OF A STEAM TURBINE HP ROTOR BLADE STAGE CONCERNING MATERIAL EFFORT, . . 167

Table 1.

Cases used in numerical analyses

\begin{tabular}{|c|c|c|c|c|}
\hline Model & Sector angle & $\begin{array}{c}\text { Number of blades } \\
\text { in the cyclic model }\end{array}$ & $\begin{array}{c}\text { Number of blades } \\
\text { in the rotor disc }\end{array}$ & $\begin{array}{c}\text { Continuity conditions } \\
\text { for the shroud }\end{array}$ \\
\hline A & $2.3682^{\circ}$ & 1 & 152 & entire circumference \\
\hline B & $90^{\circ}$ & 38 & 152 & inside the segments $13+13+12$ \\
\hline C & $30^{\circ}$ & 13 & 156 & entire circumference \\
\hline D & $30^{\circ}$ & 13 & 156 & inside the segment \\
\hline
\end{tabular}

The model A was analyzed to find the initial stress state of the structure and to evaluate the rheological phenomena. The model had the actual number of rotor blades and the continuous shroud. The two variants depended on the installing of the blades, and spacers inside the disc were considered. In the first variant, the initial clearance equal to $0.03 \mathrm{~mm}$ was assumed between the blades and the spacers at the beginning of the analysis. In the second variant, the adjacent surfaces of blades and spacers were in touch without any clearance. The model B was used for modal analysis. It had a reduced density of discretization, and the simplified method of contact modeling with the bonded degrees of freedom was applied. Due to the requirements of cyclic symmetry, the separate shroud segments were reordered to cover the following numbers of blades: 13-13-12-13-13-12-13-13-12-13-13-12 instead of $10 \times 13+2 \times 11$.

The models $\mathrm{C}$ and $\mathrm{D}$ were characterized by the modified geometry of the rotor disc with a slightly greater number of the blades and spacers. These models were used to investigate the influence of the shroud discontinuity on the displacement and stress levels. The applied isotropic material models were based on the data available in the literature and standards [3, 5]. The material of the disc was the steel 26H2MF. The other parts, including the blades, the spacers and the shroud, were modeled as the steel 13HMF. Some rheological data for this material were not available, and because of that they were supplemented by the data found for the steel 1.7733 of similar chemical composition. The material properties were constant or varied linearly as a function of temperature (Tab. 2).

In order to assess the stress state of material, we used the equivalent von Mises stress $\sigma_{\text {eqv }}$ and the equivalent plastic strain $\varepsilon_{\text {pleqv }}$ criteria [2,6]. The initial displacements were caused by the mass, thermal and surface load. For the creep analysis, the initial transient creep period was neglected, and the Norton's creep model for the steady creep period was used. The creep strain rate was evaluated as (1):

$$
\frac{\mathrm{d} \varepsilon_{c r}}{\mathrm{~d} t}(T)=B(T) \sigma^{n(T)} .
$$


Material properties

\begin{tabular}{|l|l|l|}
\hline Property & $13 \mathrm{HMF}$ & $26 \mathrm{H} 2 \mathrm{MF}$ \\
\hline Young's Modulus $[\mathrm{MPa}]$ & $2.1732 \cdot 10^{5}-82.68 T^{\circ} \mathrm{C}$ & $2.1275 \cdot 10^{5}-83.50 T^{\circ} \mathrm{C}$ \\
\hline Poisson ratio & 0.3 & 0.3 \\
\hline Yield stress [MPa] & $319.2-0.28 T^{\circ} \mathrm{C}$ & $564.85-0.41 T^{\circ} \mathrm{C}$ \\
\hline Tangent modulus [MPa] & 5000 & 5000 \\
\hline Density $\left[\mathrm{g} / \mathrm{cm}^{3}\right]$ & $7.80-3.17 \cdot 10^{-4} T^{\circ} \mathrm{C}$ & $7.83-3.25 \cdot 10^{-4} T^{\circ} \mathrm{C}$ \\
\hline Thermal expansion coefficient $[1 / \mathrm{K}]$ & $1.20 \cdot 10^{-5}-3.0 \cdot 10^{-9} T^{\circ} \mathrm{C}$ & $1.27 \cdot 10^{-5}-2.05 \cdot 10^{-9} T^{\circ} \mathrm{C}$ \\
\hline Friction coefficient & 0.1 & 0.1 \\
\hline
\end{tabular}

The creep constants $B(T)$ and $n(T)$ were determined based on the creep limit data $R_{1 / T / 10000}$ and $R_{1 / T / 100000}$ (creep strain [\%] / temperature [C] / time [h]) available in the literature $[3,5]$. Since the temperature distribution in the rotor disc was assumed to be constant in time, the creep strain rate at a given point of the structure was evaluated for a constant temperature and depended on the change of the equivalent stress in time. The creep constants were determined for a set of temperatures and then introduced into the ANSYS program. The creep strain according to the Norton's law might be expressed as a linear function of time with a coefficient of proportionality depending on the temperature. Thus, the coefficient $k(T)$ was defined as a function of the creep constants (2):

$$
k(T)=\frac{\varepsilon_{c r}(T)}{t}=B(T) \sigma^{n(T)} .
$$

The constants $k_{1}(T)$ and $k_{2}(T)$ have been determined on the basis of the known values of the creep limits for the creep strain equal to one percent and different times:

$$
k_{1}(T)=\frac{1 \%}{10000 h}=B(T) R_{1 / T / 10000}^{n(T)} ; \quad k_{2}(T)=\frac{1 \%}{100000 h}=B(T) R_{1 / T / 100000}^{n(T)} .
$$

Thus, dividing the second equation by the first one:

$$
\begin{gathered}
n(T)=\frac{\ln \left(\frac{k_{2}(T)}{k_{1}(T)}\right)}{\ln \left(\frac{R_{1 / T / 100000}}{R_{1 / T / 10000}}\right)}=\frac{\ln 0.1}{\ln \left(\frac{R_{1 / T / 100000}}{R_{1 / T / 10000}}\right)} ; \\
B(T)=\frac{k_{1}(T)}{R_{1 / T / 10000}^{n(T)}}=\frac{0.01}{10000 h \cdot R_{1 / T / 10000}^{n(T)}} .
\end{gathered}
$$

The results of creep data evaluation are shown in Fig. 2. 
FE ANALYSIS OF A STEAM TURBINE HP ROTOR BLADE STAGE CONCERNING MATERIAL EFFORT,.. . 169
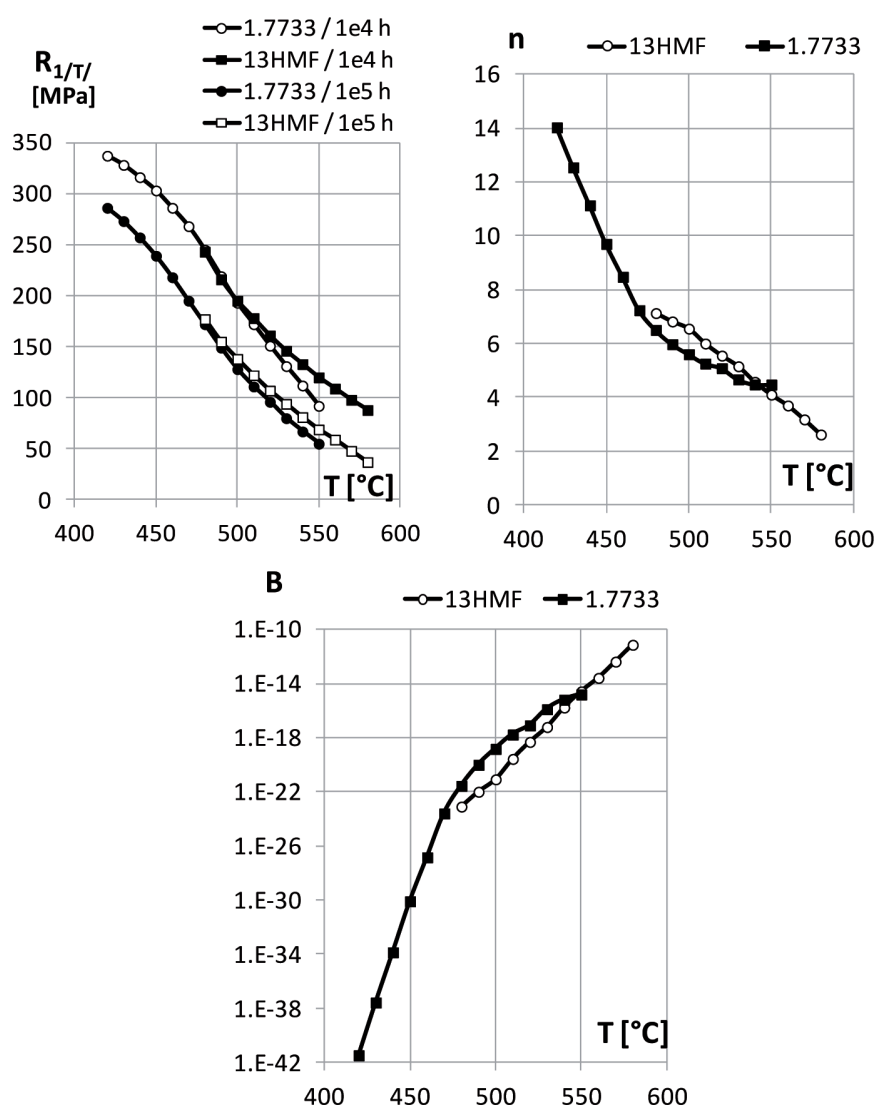

Fig. 2. The creep limits and constants according to Norton's law as a function of temperature

The material damage as a result of a steady state creep was estimated using the time-temperature equivalence principle and based on the available data on the Larsson-Miler parameter [4], which remains constant when the stress is not changed (5):

$$
p_{L M}=T\left(\log t_{r}+C\right)
$$

where: $T$ was the temperature in degrees Kelvin, $t_{r}$ - life time, $C$ - material constant. The constant $C$ for the steel $13 \mathrm{HMF}$ was 16.006 and for the steel 1.7733 , which was the equivalent of $26 \mathrm{H} 2 \mathrm{MF}$, this constant was 20 [5]. The relationships between the Larsson-Miler parameter and the equivalent stress taken from the literature were approximated by the third-degree polynomials, and shown in Fig. 3:

$$
\begin{aligned}
& p_{L M}=-3.543 \cdot 10^{-5} \sigma^{3}+4.186 \cdot 10^{-2} \sigma^{2}-23.331 \sigma+18734.71 \quad(13 \mathrm{HMF}) \\
& p_{L M}=-4.569 \cdot 10^{-4} \sigma^{3}+0.227 \cdot \sigma^{2}-47.747 \sigma+22671.92 \quad(1.7733)
\end{aligned}
$$




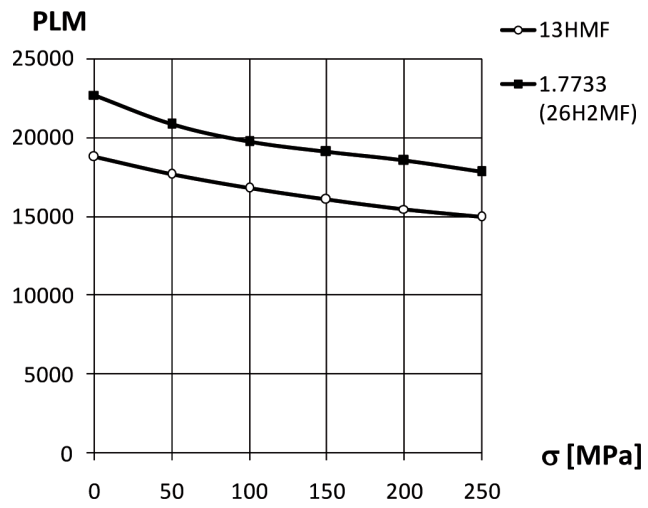

Fig. 3. Larsson-Miler parameter versus stress [5]

The failure time due to creep for a given stress level was evaluated according to the formula (5):

$$
t_{r}=10^{\left(\frac{p_{L M}}{T}-C\right)} .
$$

Since the stress in the model was not constant over time because of relaxation, the calculation of the creep cumulative damage was carried out considering the fact that the simulation was performed with the $\mathrm{n}$ time steps. It was assumed that the nodal von Mises stress $\sigma_{a v i}$ for a given increment of time $\Delta t_{i}$ was an average value between the beginning and end of the time step. The life time $t_{r i}$ for the stress level $\sigma_{a v i}$ at a given point was determined from formula (7), by calculating the Larsson-Miler parameter from formula (6). The cumulative damage due to creep $Z_{t}$ was then calculated by summing the fractions $\Delta t_{i} / t_{r i}$ over the time of the creep analysis [6]:

$$
Z_{t}=\sum_{i=1}^{n} \frac{\Delta t_{i}}{t_{r i}}
$$

Numerical simulations were performed for the three types of load conditions: the mass forces from the rotational speed of $3000 \mathrm{rpm}$, the constant pressure on the concave surfaces of the blades which was chosen so as to produce the power of $4 \mathrm{MW}$ on the rotor disc and the temperature distribution from the time of 20 hours after the start-up of the turbine (Fig. 4). The temperature distribution was treated as a steady state, and was obtained from the previously performed thermal analysis of the discrete model of the entire shaft containing all rotor discs. In the model of the A1 rotor disc, only one cross-sections of the shaft was supported. The cross-section having a smaller diameter was constrained in the circumferential and axial directions but the radial displacement was free. The second cross-section of a greater diameter was not constrained. The side cross-sections were coupled by using the cyclic symmetry conditions depending on the way of the shroud modelling (Tab. 1). 

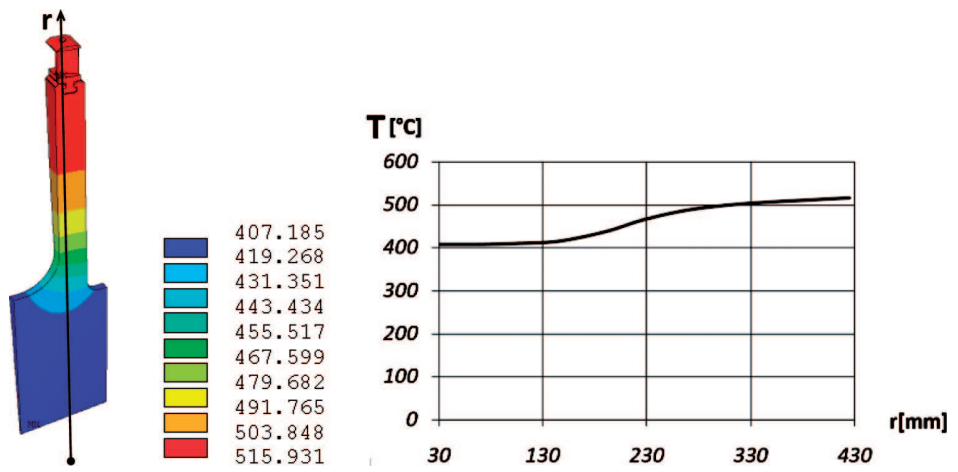

Fig. 4. Temperature distribution in the A1 rotor disc after 20 hours from the start-up versus the disc radius

\section{Results of structural creep analysis}

The first step was to establish the initial state from which the rheological phenomena would be started. The model A (Tab. 1) was used to evaluate the stress state at a starting time, and the influence of the effect of the clearance between the blades and spacers was examined. Then, the extension of the blades in time due to creep was investigated, and the stress relaxation in the components of the rotor disc was found. The displacements of the entire model in the radial and axial directions are shown in Fig. 5. The radial displacements at the tip of the blade are shown in Tab. 3 and Fig. 6a. The presented time period of 29.7 years corresponds to the value of the creep damage $Z_{t}=100 \%$ in one of the nodes belonging to the blade. The change

a)

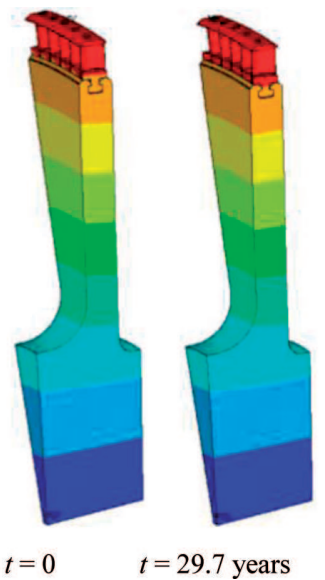

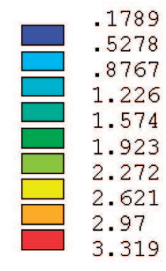

$[\mathrm{mm}]$ b)

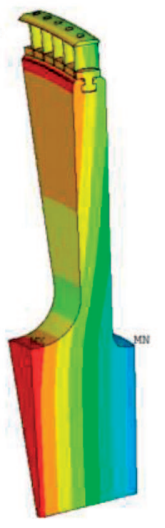

$t=0$
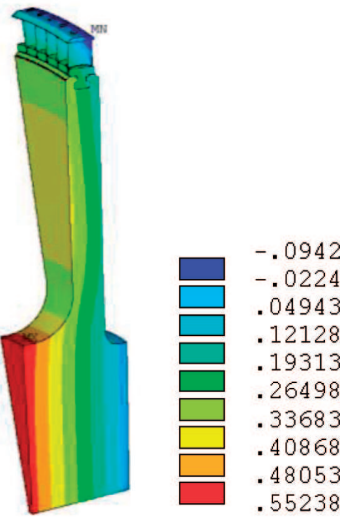

$t=29.7$ years $\quad[\mathrm{mm}]$

Fig. 5. The radial (a) and axial (b) displacements in the model A with the initial clearance of $0.03 \mathrm{~mm}$ 
in the blade length caused by creep was slightly greater for the model with the initial clearance, and was equal to $0.0067 \mathrm{~mm}(0.0053 \mathrm{~mm}$ for the model without the initial clearance). Despite the fact that these values were very small, the presence of contact forces between the blades and spacers reduced the creep displacement.

Table 3.

Material properties of the experimental beam and transducers

\begin{tabular}{|c|c|c|c|}
\hline \multirow{2}{*}{ Model A } & \multicolumn{3}{|c|}{ Radial displacement at the tip of the blade [mm] } \\
\cline { 2 - 4 } & time $=0$ & time $=29.7$ years & creep increment \\
\hline with the initial clearance of $0.03 \mathrm{~mm}$ & 3.206 & 3.269 & 0.063 \\
\hline without the initial clearance & 3.206 & 3.268 & 0.062 \\
\hline
\end{tabular}

a)

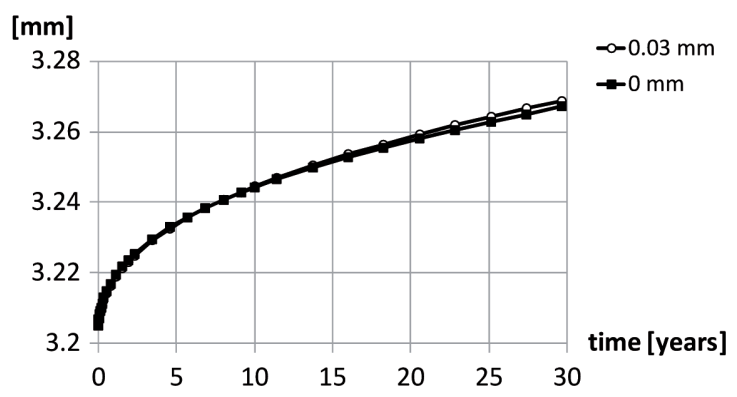

b) $[\mathrm{mm}]$

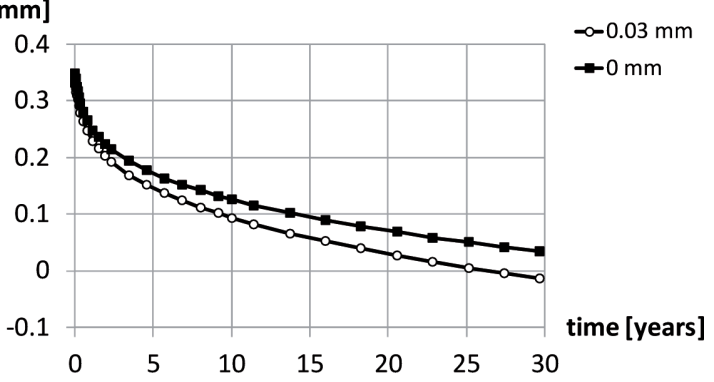

Fig. 6. The radial (a) and axial (b) displacements in the model A at the tip of the blade

The maximum value of the axial displacement occurred at the free end section of the shaft as a result of thermal expansion, and this value practically didn't change over time (Fig. 5b).The axial displacement of a blade occurred mainly because of the shape of the turbine shaft. The difference in diameters of the shaft in front of and behind the A1 rotor disc resulted in an elastic displacement of the disc in the axial direction towards the bigger diameter of the shaft (inlet side) and then subsequent back deformation of disk and blades toward the smaller diameter by creep effects caused by the surface 
load on the blades. The axial displacement of the blade was also caused by creep of the blade root. Additionally, the clearance between the blade and spacer allowed the blade to move axially due to the mass forces. Since the center of gravity of the blade was placed nearer its leading edge, the clearance was the cause of a backward rotation of the blade. The maximum axial displacement (Fig. 6b) at the tip of a blade for the time of 29.7 years was greater in the model with the clearance $(-0.35 \mathrm{~mm})$ compared to the model without the clearance $(-0.30 \mathrm{~mm})$. The relative displacement of the tip measured from the root of a blade was, respectively, $-0.223 \mathrm{~mm}$ and $-0.185 \mathrm{~mm}$. So, the deviation of the blades from the plane of the rotor after 29.7 years was estimated as, respectively, $0.26^{\circ}$ and $0.22^{\circ}$.

The stresses in the blade became lower over time and their distributions was more uniform (Fig. 7a). Similar results were obtained for the models without and with the initial clearance. The latter model gave slightly greater equivalent stress in the blade root than in the blade neck. These differences were vanishing over time. Fig. 11 shows changes in the equivalent stress over time at the selected point of the notch placed in a blade root. The most intensive decrease in stress was observed in the notch at the base of the blade root. The most important was the period of 4 years in which the effect was most visible. In the period from 4 to 10 years, the changes in stress were not so intense and then remained almost constant. The maximum value of von Mises stress in the notch was initially equal to $179 \mathrm{MPa}$, after 10 years it decreased to $90.2 \mathrm{MPa}$ which was $50 \%$ of the initial value, and finally it reached 78.9 $\mathrm{MPa}$ after 29.7 years. The yield stress of the blade material in the temperature of $515.9^{\circ} \mathrm{C}$ was $174.7 \mathrm{MPa}$. This meant that in the initial period the plastic strain occurred locally in a small number of finite elements

a)

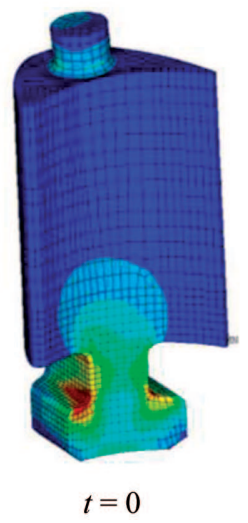

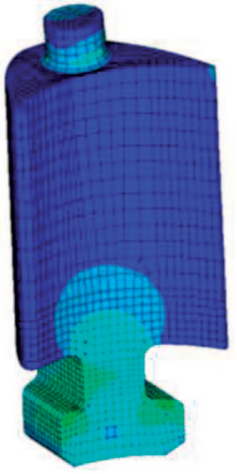

$t=10$ years b)

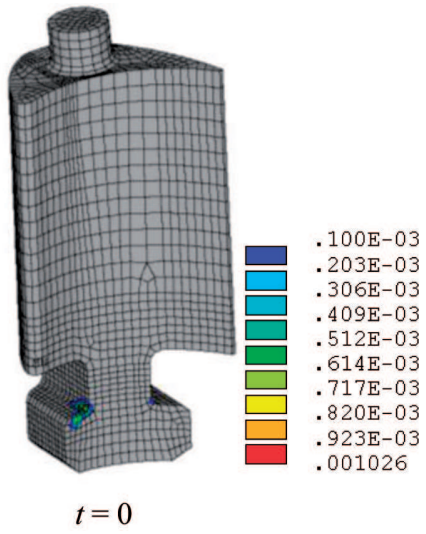

Fig. 7. Equivalent von Mises stress (a) and equivalent von Mises strain (b) in the blade for the model A with the initial clearance of $0.03 \mathrm{~mm}$ 

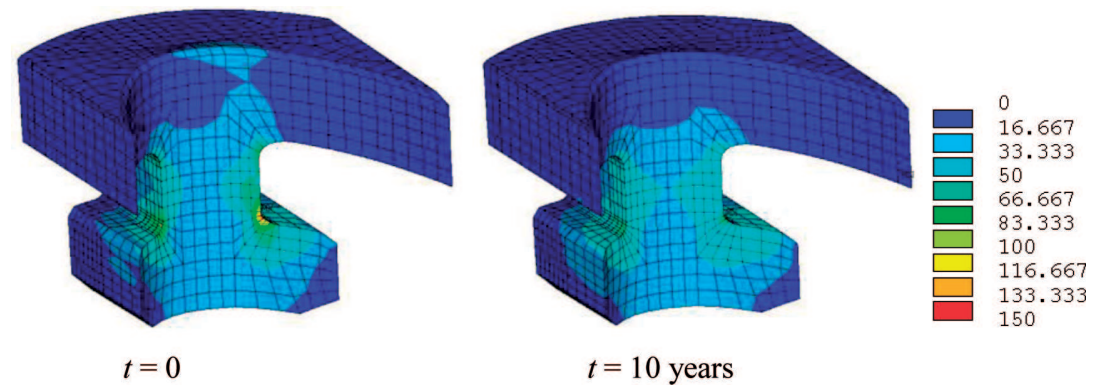

Fig. 8. Equivalent von Mises stress in the spacer for the model A with the initial clearance of $0.03 \mathrm{~mm}$

placed on the surface of the notch (Fig. 7b) and the strain was caused by the applied loads which didn't change until the end of the creep analysis, so the plastic strains also remained constant. The equivalent strain in the region of a stress concentration reached the maximum value of $1.026 \cdot 10^{-3}$, which was relatively small. This was mostly because of modelling the edge of the blade root without taking into account the fillet radius and might be neglected in the strength analysis. Hence, it was found that the creep proceeded generally in an elastic state. The equivalent stress in the blade at the level of about $60 \mathrm{MPa}$ was reached after 10 years in a cross-section of the neck.

The change in the stress in the spacer over time due to creep was similar to that observed in the blade. The maximum values of equivalent stress after 10 years decreased to about $37 \%$ of the initial value, from 146 to $55 \mathrm{MPa}$ (Fig. 8). The effect of the initial clearance between the blade and the spacer was also small, as shown in Fig. 11. In the spacer, there were no plastic deformation and the maximum equivalent stress in the notch of the spacer stabilized at $50 \mathrm{MPa}$ after the time of investigation. The maximum value of the equivalent stress in the shroud after 10 years decreased to about half of the initial value, from 98 to $49 \mathrm{MPa}$ (Fig. 9). The effect of the initial clearance between the blade and the spacer was negligible (Fig. 11).
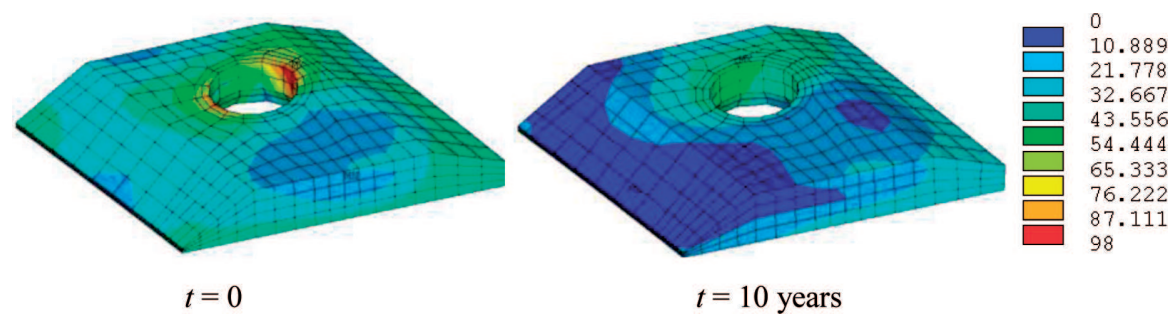

Fig. 9. Equivalent von Mises stress in a shroud for the model A with the initial clearance of $0.03 \mathrm{~mm}$ 
Due to different diameters of the shaft before and behind the A1 rotor disc, there appeared, besides the radial displacement (Fig. 5b), also a displacement in the transverse direction of the shield. Consequently, the stress in the disc was not uniform, and the highest stress occurred at the notch in the shield from the side where the diameter of the shaft was smaller (Fig. 10). There were no plastic deformation in the disc and the shaft. The maximum equivalent stress in the notch decreased in time and stabilized at about

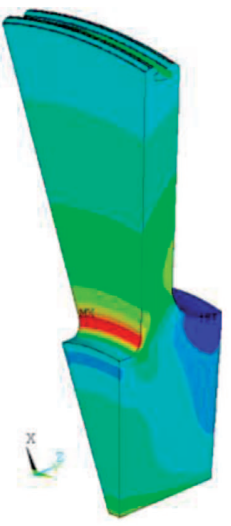

$t=0$

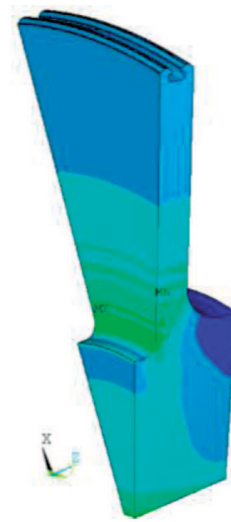

$t=10$ years

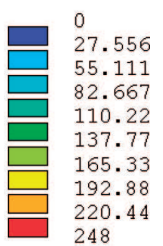

248

Fig. 10. Equivalent von Mises stress in the shield and the shaft for the model A with the initial clearance of $0.03 \mathrm{~mm}$

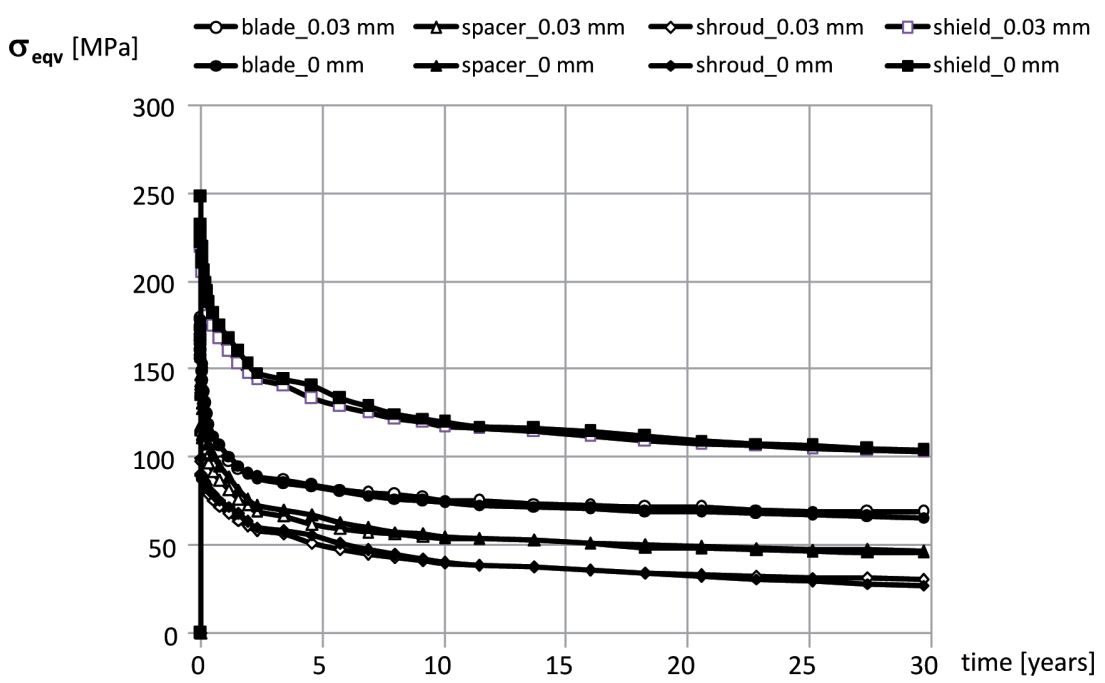

Fig. 11. Maximum of the equivalent von Mises stress in the most loaded points of the A1 rotor disc 
$100 \mathrm{MPa}$. We didn't observe any influence of the clearance between the blade and the spacer on the stress magnitude in the shield (Fig. 11).

The influence of discontinuity in the shroud segments was examined using the models $\mathrm{C}$ and $\mathrm{D}$ (Tab. 1). As it was apparent from the design documentation, one ensured the spacing between adjacent shroud parts with a maximum value of $0.2 \mathrm{~mm}$. For the considered time period of 10 years, the discontinuous shroud segments (model D) extended due to creep in both the radial and circumferential directions, but not so much that the gap of 0.2 $\mathrm{mm}$ was closed. Figure 12 shows the circumferential displacement along the $\mathrm{s}$ direction. For the model $\mathrm{C}$ with a continuous shroud, the circumferential movement was obviously constant, whereas in the case D of discontinuous shroud, this movement changed almost linearly with increasing circumferential coordinate. The slope of the linear characteristic decreased with time, so that the circumferential extension of the bandage was reduced after 10 years from $0.047 \mathrm{~mm}$ to $0.037 \mathrm{~mm}$. Both values were relatively small in comparison with the gap between the adjacent shroud segments.

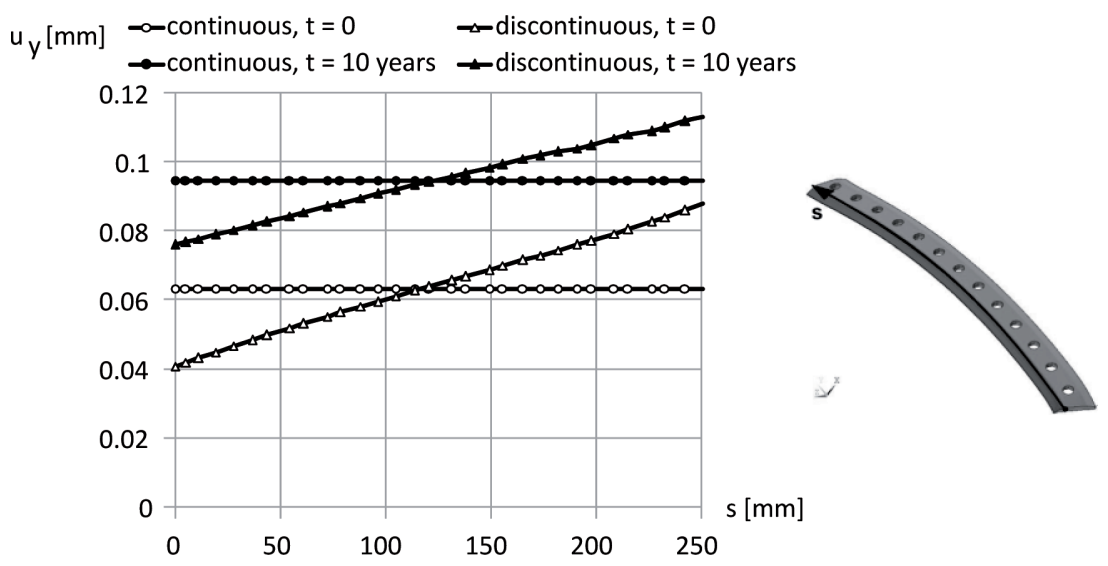

Fig. 12. Circumferential displacement in the shroud segment

Figures 13 and 14 show the differences between circumferential displacements and equivalent stresses calculated for the model $\mathrm{C}$ with the continuous shroud and those for the model D with the discontinuous shroud. Positive values on a contour scale indicate the regions where the model with the continuous shroud overestimates the results. Because of the fact that the assumption about the shroud continuity was inconsistent with reality, the regions of negative difference were more significant. This non-uniform stress distribution was mainly because of the surface load applied on the blade surfaces. In Fig. 14 one can see that the regions of maximum differences occur in the rear tip of the blade, which results from the contact interaction with the shroud. In the regions in which the model with the continuous bandage 
underestimated the stress value, one can observe the decrease in the stress difference in time. The differences between the displacements and stresses in the spacers and those in the shield resulting from different methods of the shroud modeling were negligible, and therefore they are not shown.

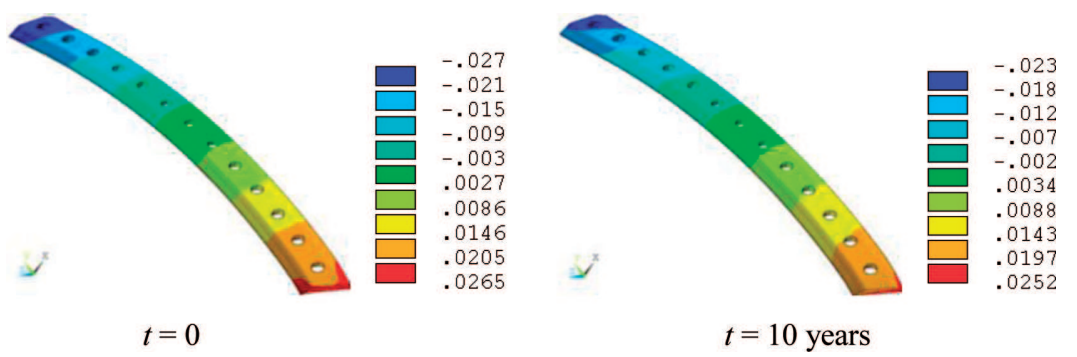

Fig. 13. Difference in the circumferential displacement between models C and D [mm]

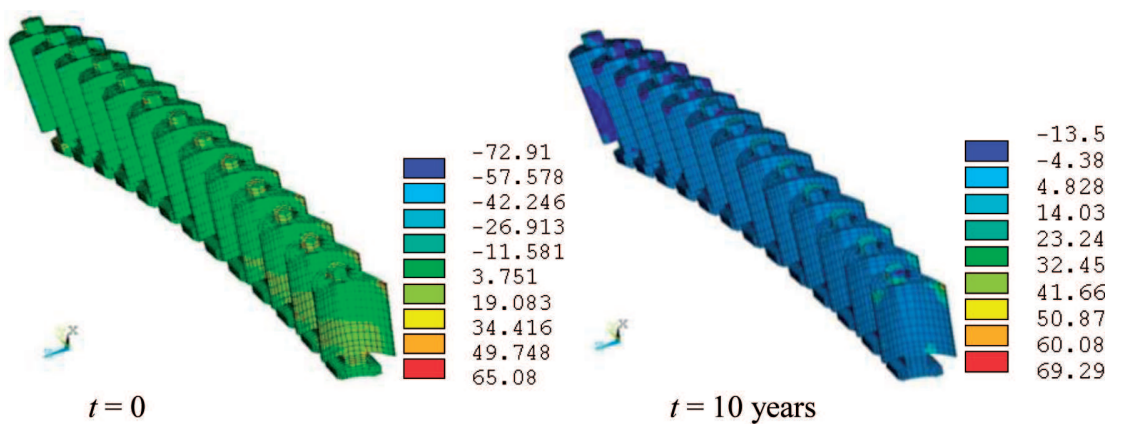

Fig. 14. Difference in the equivalent von Mises stress between models C and D [MPa]

\section{Results of a creep damage calculation}

Calculations of the cumulative creep damage $Z_{t}$ was carried out based on numerical simulation according to two approaches. The first one was the local damage assessment in some points of the rotor disc, such as the notches on the surface of the blade, spacer, shroud and a blade groove of the shield. The second one was the global damage assessment defined in important cross-sections, such as the blade neck section. The time period of 29.7 years $\left(2.6 \cdot 10^{5}\right.$ hours) was chosen. The points of the maximum local damage did not coincide with the points where the equivalent stresses reached maximum values. In comparison to the results of stress analysis, the effect of the initial clearance between blades and spacers was more significant for the local creep assessment. Particularly, the creep damage in the blade notch for the case in which there was an initial gap of $0.03 \mathrm{~mm}$ was higher and locally reached 
$105 \%$ compared to $92 \%$ obtained for the model without a gap (Fig. 18). Nevertheless, the global damage evaluated in the blade neck section in both cases was very similar and reached only about $17 \%$ (Fig. 15). The global creep damage values in the spacer and the shroud were smaller than those obtained for the blade (Fig. 16), and the effect of the initial clearance was very small (Fig. 18).

a)

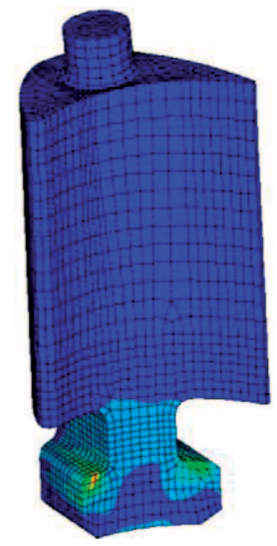

b)

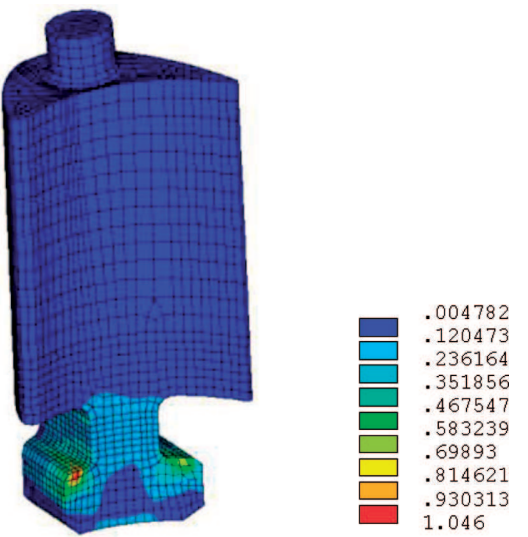

Fig. 15. Creep damage in the blade after 29.7 years: a) model A without the initial clearance, b) with the initial clearance of $0.03 \mathrm{~mm}$

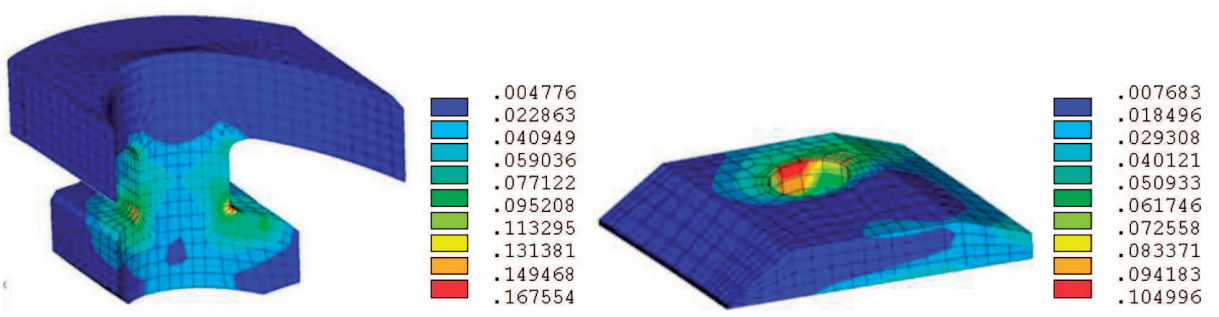

Fig. 16. Creep damage in the spacer and shroud after 29.7 years for the model A with the initial clearance of $0.03 \mathrm{~mm}$

The creep damage in the shield at the point of stress concentration at the base of the shaft was low (Fig. 17) due to a relatively low temperature, which was between $413^{\circ} \mathrm{C}$ and $438^{\circ} \mathrm{C}$ along the contour of the notch at the base of the shaft. The maximum local creep damage existed inside the blade groove of the shield and reached more than $60 \%$ after 29.7 years. The analysis results coincided with the ones observed in the actual design of the rotor disc [10]. As for the blade, a greater value of local damage occurred for the model with the initial clearance (Fig. 18).

The course of the creep damage for the period of 29.7 years in the most affected points of the rotor disc is shown in Fig. 18. Unlike the equivalent 

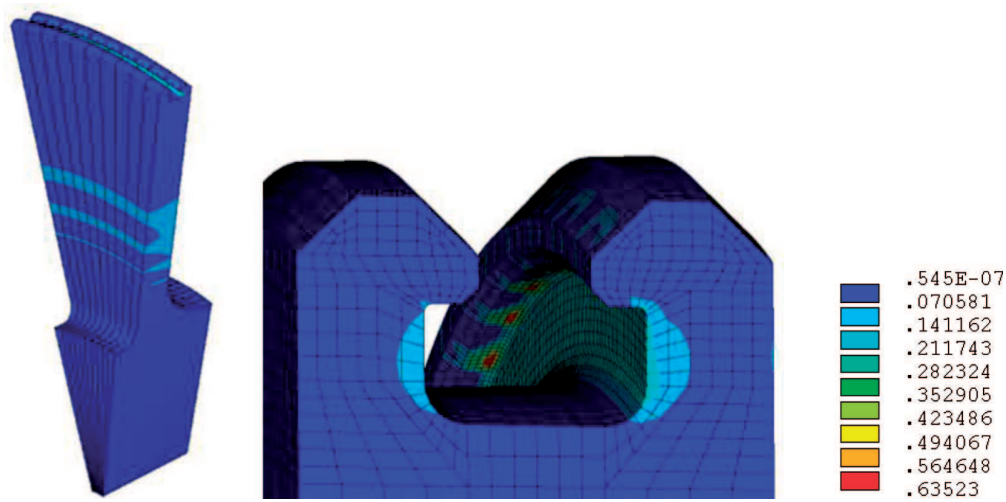

Fig. 17. Creep damage in the blade groove of the shield after 29.7 years for the model A with the initial clearance of $0.03 \mathrm{~mm}$

stress, the greatest creep damage occurred at the blade not in the shield, mainly due to relatively high temperature. Although the effect of the initial clearance between the blades and spacers on the stress in the blade was small and vanishing in time, mainly due to stress relaxation in the contact area, the local creep damage was greater for the model with the initial clearance, probably because of an additional movement of the blade. In that model, the blade rotated slightly because of its mass and pressure loads until the edge of the blade foot touched the surface of the blade groove in the shield.

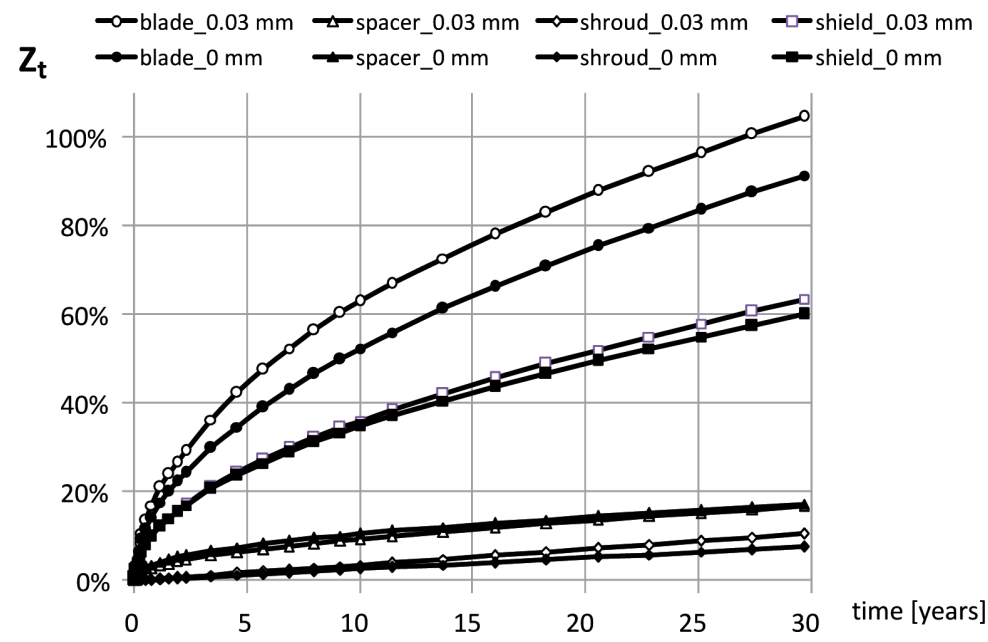

Fig. 18. Local creep damage evaluated in the notches of the rotor disc parts 


\section{Results of modal analysis}

For the calculation of natural frequencies and mode shapes we used the model B (Tab. 1). Initial loads as mass forces, the pressure on the blades and the effect of temperature were included, and the Block Lanczos method was used. Taking into account the fact that the vibrations of a rotor disc are mainly forced by the non-uniform conditions of the flow that acts on the blade, we evaluated the potentially dangerous range of possible excitations. The excitations sources are the two nozzle ring brackets $(M=2)$ and the guide blades $(M=101)$. Potentially dangerous are these excitations which may by expressed by the circumferential expansion as: $F(t)=\cos (M \cdot 2 \pi f t)$ and optionally their second harmonic. The mode shape of the nodal diameters $M$ of the blade ring having $N$ blades in the general case may be excited by the flow forces represented as (9):

$$
F(t)=\cos (2 \pi(n N \pm M) f t)
$$

where $n=0,1,2, \ldots N$ is a natural number and $f=50 \mathrm{~Hz}$ - the frequency at the running speed $R S=100 \pi 1 / \mathrm{s}$ )

Considering that the maximum possible number of nodal diameters for a blade ring is equal to $N / 2$ for an even number of blades or $(N-1) / 2$ for an odd number, in the case of the A1 rotor disc, for $N=152$, we predicted potentially dangerous interferences between the natural vibrations and excitations. The first order interference may occur when the mode shape has 2 nodal diameters and the excitation comes from the two nozzle ring brackets, or when the mode shape has 51 nodal diameters and the excitations source are 101 guide blades. In fact, using formula (9) we get: $51=1 \cdot 152-101$. Obviously, the interferences appear if the frequencies are, respectively, equal to $100 \mathrm{~Hz}$ $(2 R S)$ or $5050 \mathrm{~Hz}(101 R S)$. Moreover, the weaker second order interferences were taken into account. They may occur when the mode shape has 4 nodal diameters and the second harmonic of excitation from the two nozzle ring brackets is considered, or when the mode shape has 50 nodal diameters and the second harmonic of excitation comes from 101 guide blades $(2 \cdot 101=$ $=1 \cdot 152+50$ ). Although the latter interference is possible, it is negligible because it occurs at a very high and strongly damped frequency of $10100 \mathrm{~Hz}$. The results of modal analysis are shown in Fig. 19 as a SAFE diagram (Singh Advanced Frequency Evaluation Diagram) [1]. Red circles represent the interferences of the first order and white circles - those of the second order. The rhombs are the results of the modal analysis. It should be noted that the resulting differences between the natural frequencies and the excitations were as high as several hundred percent (Fig. 19b) which confirmed that the rotor disc was properly designed. Some mode shapes of the second harmonic are shown in Fig. 20. 

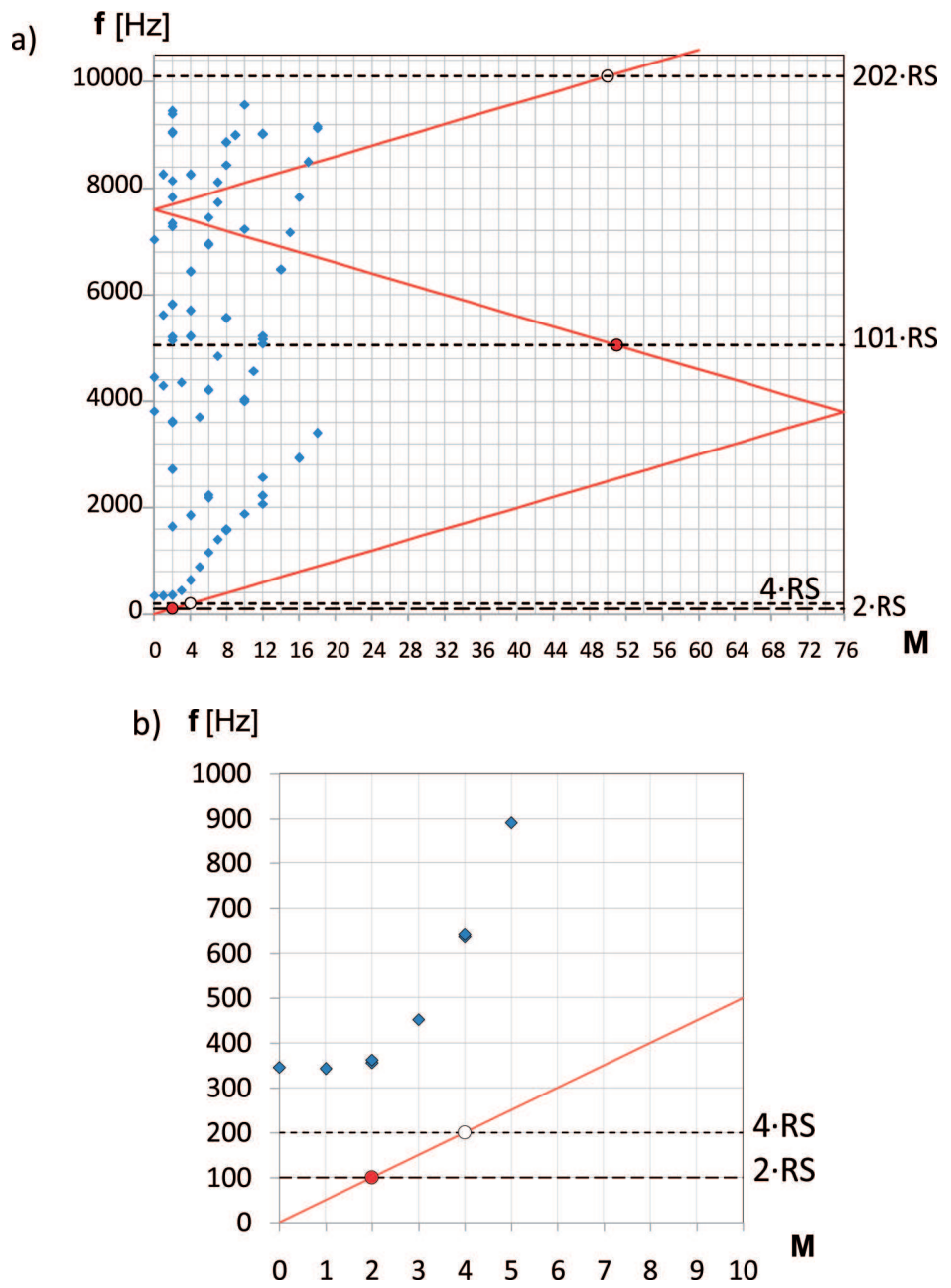

Fig. 19. SAFE diagram for the A1 rotor disc

(a - nodal diameters to $76, \mathrm{~b}$ - nodal diameters to 10 )
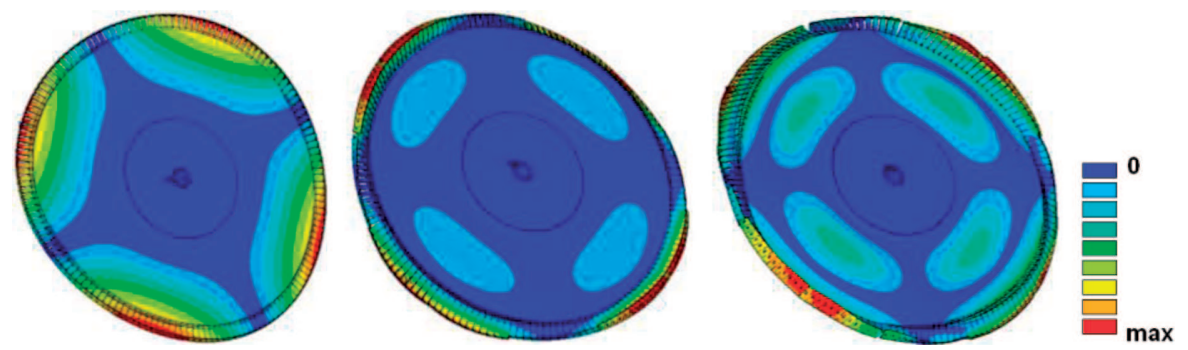

Fig. 20. Examples of mode shapes of the second harmonic: the first of $355.478 \mathrm{~Hz}$, the sixth of $1653.1 \mathrm{~Hz}$ and the fourteenth of $2733.4 \mathrm{~Hz}$ (the summary displacement was presented) 


\section{Discussion}

A single rotor disc was a part of the entire turbine. At the beginning of the analysis, the selection of the model boundaries was made and the two cross-sections of the shaft were chosen to limit the model space. In one of them, the overrigid support was applied (both circumferential and axial degrees of freedom were constrained) and the second cross-section was not constrained. Therefore, the remaining part of the shaft was replaced by the artificial boundary conditions which locally disturbed the stress distribution and the natural frequencies of the rotor disc, but their influence was not so significant in the outer part of the structure.

Furthermore, one of the difficulties in analyzing a single rotor disc was the need to make thermal calculations for the whole turbine in order to obtain a temperature distribution. It was known that the temperature had a great importance in the structural analysis of the turbine. For practical reasons, the pressure on the blades was calculated on the basis of the known power generated at the chosen rotor disc. The distribution of pressure on the blade did not really matter because of the fact that the flow force in the analysis of the steady state should be averaged due to pressure pulsations caused by the guide blades and other parts of the turbine.

In the presented simulation, the holes in the shield made for pressure equalization between the adjacent rotor discs were neglected due to the requirements of cyclic symmetry conditions. The cyclic structural analysis made it possible to use a good discretization of the blade portion of the rotor disc and to reduce the computation time. As the holes did not change the stiffness of the shield significantly, their impact was studied separately and was not presented. The A1 rotor disc was characterized by the difference in diameters of the shaft on both sides of the rotor, which was the reason for the significant increase in stress at the base of the shield. Therefore, this region should be investigated considering the problem of a potential fatigue, particularly because of the fact that the all normal stresses at this point were positive. As was shown, the influence of the initial clearances between the blades and spacers was apparent only in the initial creep period and then vanishing due to stress relaxation.

Stress magnitudes in the notches and the contact area in the finite element analysis strongly depend on the mesh size. The regular mesh was applied and the proper shape of finite elements was ensured in the predicted regions of high stresses. The assumed element size used in presented stress analysis was sufficient (108 elements in the blade neck cross-section). Nevertheless, the effect of discretization density was not investigated and hence the results should not be used in the fatigue or fracture propagation analyses. The highest 
stress magnitude occurred rather as the result of the notch phenomenon than due to contact interaction. It is shown in Fig. 7a, where the maximum equivalent stress appears at the point where the contact was not observed. Additionally, the stress levels in the concentration regions decreased rapidly at the beginning of the creep process, as it is shown in Fig. 11.

The creep displacement magnitudes obtained for the blade were relatively small. However, when the numerical results using Norton's model are known, it may be compared to the measurements carried out on the blades during the inspection, and it probably may help to determine whether the creep process reached its third stage characterized by the accelerated strain rate [6].

The creep damage calculation gave the results that could be interpreted both as a local exhaustion of the creep life in a certain point of the structure, or as a global quantity which was the average value of damage at the entire cross sections of particular importance, such as the blade neck. However, the local creep damage at some points had no practical importance, since it depended mainly on simplifications of geometry and the discretization used in the numerical model, while the creep damage in a global sense at the critical sections of the structure might have a practical importance in assessing the allowable working time. On the basis of the creep calculation it was found that the time after which the blades must be replaced due to creep damage (about $17 \%$ after nearly 30 years) can be much longer than the time which is allowable because of the corrosion progress during exploitation. According to the literature [6], the critical value of the creep damage in a turbine design is less than $100 \%$ and usually depends on the material. For example, in the A.S.M.E standard the critical value is of $75 \%$. After reaching this value, the systematic non-destructive testing of the rotor element should begin and the supervision should be increased due to the greater likelihood of the damage [6].

In the case of the cyclic modal analysis it was necessary to model the shroud as a set of separate segments. Taking into account that the shroud segment included 12 or 13 blades and that the three adjacent segments were analyzed, a weaker discretization was used to reduce the number of degrees of freedom and to shorten the time of analysis. Additionally, the bonded contact was used, which could artificially increase the stiffness of the outer part of the rotor disc. It could also increase the natural frequencies of vibrations, but this effect was limited because of the fact that the clearances between the rotor disc parts were actually small. Since the modal analysis did not reveal any coincidence between the natural frequencies of vibration and the flow excitations coming from the stator parts, therefore the A1 rotor disc can be considered as a safely detuned from to the potentially dangerous dynamic interferences of the first and the second order. 


\section{Conclusions}

The main objective of presented analyses was to provide information about the stress state and the natural vibrations for the turbine TK120 which was just inspected and dynamically re-balanced by the ZRE company. Numerical simulation were useful in the assessment of the turbine structure by identifying the most loaded points and the regions exposed to the creep damage. On the other hand, the data concerning the regions of relatively small stress found by using FE analysis can be used to collect the material for the structural studies and to perform the re-balancing process of rotor disc.

The modal analysis provided basic information about the frequencies that can be dangerous during re-balancing of the turbine. It was also supplemented with the dynamic analysis of the whole turbine rotor, not included in this article, which took into account also the dynamic characteristics of the turbine shaft bearings. It seems that the scope of numerical simulation, presented in this paper, can support the decision-making process related to turbines repair.

\section{Acknowledgment}

This work was supported by Polish NCBR, project POIG 1.3.1-14074/12, task 4.

Manuscript received by Editorial Board, October 28, 2015; final version, March 07, 2016.

\section{REFERENCES}

[1] Singh M.: SAFE Diagram, Technology Report ST 16, Dresser- Rand Company, 1984.

[2] Ansys Theory Reference, ANSYS Inc., USA, 1984.

[3] Charakterystyki stali. Stale do pracy w temperaturach podwyższonych i obniżonych (The characteristics of steel. Steels for use at elevated and reduced temperatures). Seria D. Tom 1, Wyd. Śląsk, Gliwice 1984 (in Polish).

[4] Mazaheri M., Djavanroodi F., Nikbin K.M.: Creep life assessment of an overheated 9Cr-1Mo steel tube, International Journal of Pressure Vessels and Piping, 2010, 87, 746-752.

[5] www.keytometals.com, 2014.

[6] Chmielniak T. Kosman G., Rusin A.: Pełzanie elementów turbin cieplnych (Creep of thermal turbines components). WNT, Warszawa, 1990 (in Polish).

[7] Le May I., Furtado H.C.: Creep damage assessment and remaining life evaluation, International Journal of Fracture 97, 1999, 125-135.

[8] Jelwan Jad, Chowdhury M, Pearce G.: Creep life design criterion and its applications to pressure vessel codes, Materials Physics and Mechanics 11, 2011, 157-182.

[9] Hormozi R., Biglari F., Nikbin K.: Experimental and numerical creep-fatigue study of Type316 stainless steel failure under high temperature LCF loading condition with different hold time, Engineering Fracture Mechanics 141, 2011, 19-43. 
[10] Mazur Z., Rossette A.H.: Steam turbine rotor discs failure evaluation and repair process implementation, Engineering Failure Analysis 56, 2015, 545-554.

[11] Abu A.O., Eshati S., Laskaridis P., Singh R.: Aero-engine turbine blade life assessment using the Neu/Sehitoglu damage model, International Journal of Fatigue, 61, 2014, 160-169.

[12] Reyhani M. R., Alizadeh M., Fathi A., Khaledi: Turbine blade temperature calculation and life estimation - a sensitivity analysis H. Propulsion and Power Research, 2(2), 2013, 148-161.

[13] Orlando J.A. Goncalves Filho: Benchmark for finite element analysis of stress redistribution induced by creep damage. Computational Materials Science 33, 2005, 419-428.

[14] Naumenko K., Kostenkob Y.: Structural analysis of a power plant component using a stressrange-dependent creep-damage constitutive model Materials Science and Engineering A 510$511,2009,169-174$.

\section{Analiza MES wysokoprężnego stopnia turbiny parowej dotycząca wytężenia materiału, własności dynamicznych i oceny trwałości ze względu na pełzanie}

\section{Streszczenie}

Praca dotyczyła pierwszego stopnia wysokoprężnej części wirnika turbiny parowej TK 120. Przedstawiono metodykę doboru właściwości mechanicznych, sposobu modelowania wirnika, szacowania stopnia zużycia spowodowanego pełzaniem oraz oceny interferencji dynamicznych pomiędzy częstościami wymuszeń a częstościami drgań własnych. W obliczeniach statycznych modelu tarczy wirnika z łopatkami, przekładkami i bandażem wykorzystano cykliczną symetrię, z uwzględnieniem temperatury, sił masowych od wirowania i ciśnienia na łopatkach. Następnie przeprowadzono analizę pełzania według modelu Nortona oraz analizę modalną. W obliczeniach statycznych wyznaczono rozkłady przemieszczeń, odkształceń i naprężeń. W analizie pełzania wyznaczono przemieszczenia pełzania i relaksację naprężeń w czasie oraz oszacowano stopień zużycia ze względu na pełzanie w poszczególnych częściach wirnika turbiny. W analizie dynamicznej wyznaczono częstości i postacie drgań własnych odpowiadające poszczególnym średnicom węzłowym. Wyniki analizy modalnej przedstawiono na wykresie SAFE. Obliczenia numeryczne wykazały, że wirnik jest konstrukcją dobrze zaprojektowaną i nie wykazującą interferencji dynamicznych. 